\title{
Evaluación de Listeria spp. en muestras ambientales en una empresa de producción artesanal de quesos frescos en La Provincia de Los Santos
}

\author{
Martha Ch. de Von Chong. MSc. ${ }^{1}$, Roberto J. García G. ${ }^{2}$, Ambiorix Batista Q. ${ }^{3}$, Denisse M. Broce C. . \\ 1. MSc. en Microbiología. Profesora, Tiempo Completo, Facultad de Ciencias Naturales y Exactas, C.R.U.C., C.R.U.A, Uni- \\ versidad de Panamá, Panamá. E-mail: kmvonchong@cwpanama.net. \\ 2. Lic. en Biología con orientación en Microbiología y Parasitología, Facultad de Ciencias Naturales y Exactas, C.R.U.A., \\ Universidad de Panamá, Panamá. E-mail: vigarob@hotmail.com. \\ 3. Lic. en Biología con orientación en Microbiología y Parasitología, Facultad de Ciencias Naturales y Exactas, C.R.U.A., \\ Universidad de Panamá, Panamá. E-mail: ambiorix72@hotmail.com \\ 4. Lic. en Biología con orientación en Microbiología y Parasitología, Facultad de Ciencias Naturales y Exactas, Universidad \\ de Panamá, Panamá. E-mail: dbroce@mmm.com
}

Recepción: 2014-05-18

Aceptación: 2014-06-19

\section{Resumen}

El objetivo de esta investigación fue evaluar Listeria spp. en muestras ambientales, tomadas dentro de una empresa de producción artesanal de quesos frescos blancos, ubicada en la Provincia de los Santos, durante diciembre de 2008 a marzo de 2009. Las muestras fueron tomadas por triplicado en dos sitios de las zonas de contacto directo y dos sitios de contacto indirecto con el alimento. De las 72 muestras evaluadas, el 70\% fueron positivas para Listeria spp., encontrándose diferencias altamente significativas al $99 \%$ de probabilidad estadística, en la cuantificación entre las zonas de contacto directo (46.7\%) e indirecto $(36.3 \%)$ con el alimento.

En los aislamientos no se detectó Listeria monocytogenes en ninguna de las muestras positivas para Listeria spp.; pero se detectaron otras especies de Listeria que fueron L. seeligeri, L. grayi y L. welshimeri, demostrándose que Listeria monocytogenes podría aparecer con la probabilidad de formar reservorios potenciales, como biopelículas.

Palabras clave: Listeria spp., quesos frescos, empresa artesanal, alimentos, biopelículas

\begin{abstract}
The Listeria spp was evaluated in environmental samples taken in one artisanal production Company of White cottage cheese situated in Los Santos Province in Panama from December 2008 to March 2009. The samples were taken by triple in two places in the areas of direct contact and other two places in indirect contact with the food. Out of the 72 samples taken, the $70 \%$ was positive for the Listeria Spp., finding highly meaningful differences to the $99 \%$ of probability statistics in the quantification among the areas with direct contact (46.7\%) and indirect one (36.3\%) with the food.

In the isolations, Listeria monocytogenes was not detected in any of the positive samples for this pathogenic. Nevertheless, other species of Listeria were detected, among them: L. seeligeri, L. grayi y L. welshimeri, showing that Listeria monocytogenes may appear, with the probability to create potential reservoirs as biofilms.
\end{abstract}

Key words: Listeria spp, cottage cheese, artisanal company, foods, biofilms 


\section{Introducción}

Las bacterias pertenecientes al género Listeria spp. son cocobacilares. Gram positivas, no esporuladas, presentan de 1 a 5 flagelos peritricos que les confieren movilidad a $25^{\circ} \mathrm{C}$, pero no a $37^{\circ} \mathrm{C}$. Sus colonias son y lisas, su temperatura óptima de crecimiento está entre $30^{\circ} \mathrm{C}$ y $37^{\circ} \mathrm{C}$, pero pueden crecer a $4^{\circ} \mathrm{C}$, -psicrófilas- (Alós y otros, 2002; De la Rosa, 2003; Rojas y otros, 2006). Listeria spp. es una bacteria ubicua que se encuentra distribuida principalmente en el pasto, desde donde contamina tanto a los vegetales como a los animales y, posteriormente pasa a los alimentos.

El crecimiento de Listeria spp. está influenciado por muchas condiciones ambientales tales como la temperatura, la actividad de agua, y la accesibilidad a los nutrientes. Estas bacterias son relativamente exigentes, creciendo mejor en medios enriquecidos (Díaz y otros, 2003; Vera y otros, 2001; Moreno y otros, 2005).

La presencia de Listeria spp. se documentó como una realidad presente en plantas procesadoras de alimentos en muchos países del mundo, entre los cuales figuran, España, Estados Unidos, Perú, Venezuela, Cuba, Argentina, Chile, Inglaterra, etc. Diferentes estudios han demostrado que en estas plantas, Listeria $s p p$. puede permanecer latente durante largos períodos de tiempo (Martino y otros, 2005; Figueroa y otros, 2005; Alcázar y otros, 2006).
Además, estas bacterias se caracterizan por ser grandes formadoras de biopelículas, que son organizaciones microbianas compuestas por microorganismos que se adhieren a las superficies gracias a la secreción de un exopolímero. Diversos estudios han demostrado que las diferentes tasas de crecimiento de las cepas de Listeria spp., las interacciones con el alimento en la fase de enriquecimiento y la producción de bacteriocinas son factores que afectan la ecología microbiana de las distintas especies de Listeria; presentes en la matriz alimentaria. Esto favorece la recuperación de unas especies en detrimento de otras (Rodríguez, 2001; Pelisser y otros, 2001; Cabrera y otros, 2004).

Las colonias típicas de Listeria spp., una vez aisladas en medio selectivo/diferencial, se seleccionan para su identificación a nivel de especie, utilizando una galería de pruebas bioquímicas (Koneman y otros, 2005). Listeria spp. no es considerada como una bacteria patógena, pero si es indicativo de la posible presencia de Listeria monocytogenes; la cual es catalogada como un patógeno facultativo intracelular que puede evitar la eliminación mediada por anticuerpos (Davis y otros, 1985; Moreno y otros, 2005).

Algunos de los estudios realizados por investigadores del sector público y privado a nivel mundial, con referencia a este microorganismo en ambientes, señalan que en el ámbito 
industrial de producción alimentaria, primero se produce una contaminación en las superficies de acero inoxidable de los equipos y máquinas y; posteriormente, el producto se contamina de manera directa o indirecta con el microorganismo. En este sentido, el Servicio de Inspección de Seguridad Alimentaria y la Administración de Drogas y Alimento de los Estados Unidos, han identificado el Análisis de Peligros y Puntos Críticos de Control (HACCP), al igual que las Buenas Prácticas de Manufactura (BPM), como las estrategias más eficaces para controlar la presencia de L. monocytogenes y otras bacterias patógenas en los productos alimentarios (USDA/FDA/ CDC, 2008).

L. monocytogenes es altamente variable, y mediante la caracterización del peligro en relación a la dosis-respuesta, algunos de los factores que intervienen en esta variabilidad, según la Evaluación de Riesgos Microbiológicos, elaborada por la Comisión Mixta FAO/ OMS del Códex Alimentarius (CAC) y el Comité del Códex, sobre Higiene de los Alimentos (CCFH) (2004) son:

- Virulencia de la cepa

- Susceptibilidad del huésped

- Matriz alimentaria

- Número de bacterias ingeridas

Al mismo tiempo, esta bacteria es la causante de la Listeriosis, que es una de las enfermedades más importantes de transmisión por alimentos (ETA's). Las manifestaciones de la enfermedad en el hombre comprenden septicemia, meningitis o meningoencefalitis y encefalitis; habitualmente precedidas de síntomas parecidos a los de la gripe, incluida la fiebre. En mujeres gestantes, puede causar infecciones intrauterinas o cervicales, provocando abortos espontáneos o nacidos muertos, entre otras. La población más vulnerable ante este patógeno la conforman los ancianos, las mujeres gestantes, los recién nacidos y los individuos inmunodeprimidos (Davis y otros, 1985).

Este estudio es un precedente para las autoridades nacionales pertinentes para la ejecución de normas sobre este indicador ambiental, en materia de salud y alimentación. De igual forma, contribuirá al a realización de posteriores estudios de carácter científico, relacionados con el análisis microbiológico de superficies de contacto directo e indirecto con alimentos en plantas procesadoras. Todo ello con el fin de evitar la patogenicidad causada por el género Listeria spp. en los seres humanos. En la actualidad, y respecto a este punto, en la República de Panamá, no existe legislación alguna que lo norme.

\section{Materiales y métodos}

\subsection{Diseño experimental del muestreo}

Este se basó en clasificar el área estudiada dentro de la empresa, específicamente super- 
ficies que tienen contacto directo e indirecto con los alimentos. Las superficies fueron monitoreadas durante un período de tres meses, dentro de los cuales los sitios elegidos se muestrearon seis veces. Esta etapa se llevó a cabo durante diciembre de 2008 a marzo de 2009. Se tomaron 72 muestras en superficies ambientales dentro de la empresa, utilizando esponjas húmedas como revivificantes, en un área superficial de $90 \mathrm{~cm} 2$, la cual se adaptó a la unidad experimental. De igual forma se realizaron replicas en los sitios de las zonas de contacto directo e indirecto con el alimento.

\section{Procesamiento}

Las muestras se trasladaron a la Unidad de Investigaciones Biológicas del Centro Regional Universitario de Azuero (C.R.U.A.), en la Universidad de Panamá, en donde se realizaron los análisis microbiológicos. Cada una de las muestras se transportó dentro de su respectiva bolsa hydra sponge, conteniendo diez mililitros de caldo neutralizante Leethen, bajo refrigeración a $4^{\circ} \mathrm{C}$.

Al llegar al laboratorio se agregó a cada muestra $90 \mathrm{ml}$ de agua peptonada buferada estéril (1/9), colocándose en reposo a temperatura ambiente por cuatro horas para desestresar los microorganismos (muestra madre10-1). Luego de 4 horas, se tomó $1 \mathrm{ml}$ de la muestra madre (10-1) y se llevó al caldo de preenriquecimiento selectivo para Listeria spp. (Demi-Frazer Broth Base), suplementado con citrato que contenía $9 \mathrm{ml}$, siendo esta la segunda dilución (10-2). Del mismo modo, a partir de la segunda dilución, se tomó $1 \mathrm{ml}$ de dicho caldo y se llevó nuevamente a $9 \mathrm{ml}$ (1/9) del caldo de enriquecimiento (D. Frazer suplementado con citrato); para tener finalmente una tercera dilución (10-3). Los tubos de ensayo conteniendo ambas muestras diluidas se colocaron en una gradilla y se incubaron por 48 horas a $37^{\circ} \mathrm{C}$.

Transcurrido el período de incubación de 48 horas, se procedió a sembrar las muestras diluidas en el agar selectivo Ottaviani \& Agosti, utilizado para el aislamiento y recuento de Listeria spp. en muestras ambientales. Para ello se siguió el protocolo establecido por Biomériux (Ottaviani y Agosti 2004). Para el aislamiento en este medio se tomó $0.1 \mathrm{ml}$ de los tubos de ensayo que contenían la segunda y tercera dilución (10-2 y 10-3) respectivamente; y se procedió a sembrar por esparcido en platos petris, conteniendo agar selectivo. Cada plato inoculado fue rotulado y sellado con parafilm; luego se incubaron durante 48 horas. Los platos sembrados por semana fueron en total veinticuatro (doce conteniendo la dilución 10-2 y doce la dilución 10-3).

La cuantificación se realizó luego de transcurridas las 48 horas de incubación a $37^{\circ} \mathrm{C}$. Las colonias características de Listeria spp. crecieron de color azul verdosas, mientras que otras colonias contaminantes que no eran Lis- 
teria spp. crecieron de color blanco. Los resultados obtenidos fueron tabulados por sitios de muestre (contacto directo e indirecto), y por factor de dilución (10-2 y 10-3); al igual que por horas de lectura (24 y 48 horas). El número de colonias obtenidas en el recuento se multiplicó por su respectivo factor de dilución, para así obtener el conteo en UFC/cm2.

\section{Aislamiento y cuantificación}

Los cultivos puros se analizaron empleando la tinción de Gram para ver coloración y morfología; además de la prueba de Catalasa positiva y Oxidasa negativa. Se seleccionaron colonias que presentaron características típicas de Listeria spp., las cuales fueron sembradas nuevamente en agar Listeria monocytogenes; según Ottaviani y Agosti, las muestras fueron incubadas por 48 horas a $37^{\circ} \mathrm{C}$. Las bacterias

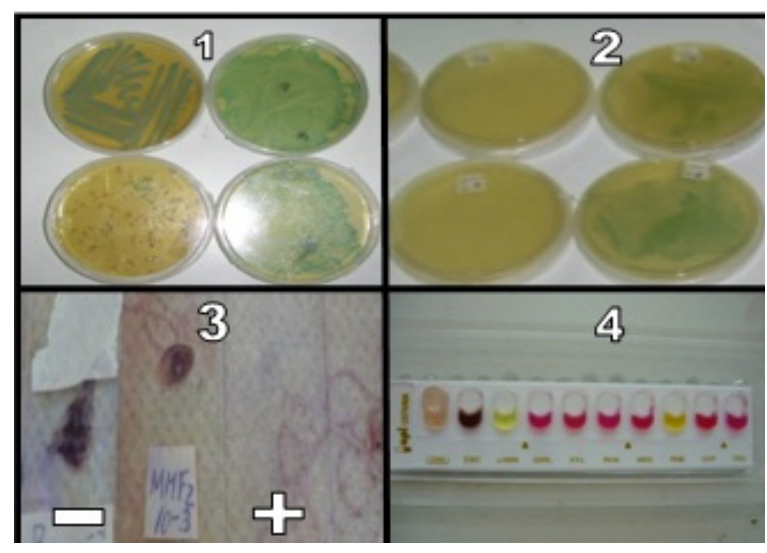

Fuente: Von Chong, M.; Batista, A.; García, R.; Broce, D. 2009. Universidad de Panamá. C.R.U.A. Facultad de Ciencias Naturales, Exactas y Tecnología. Escuela de Biología. Departamento de Microbiología.
Gram positivas, presentaron una forma $\mathrm{Coco}^{-}$ bacilar y una coloración púrpura o morada. Las placas fueron llevadas para observación, a través del microscopio compuesto de luz, utilizando aumento de 100X, en donde se observó la presencia de bacterias cocobacilares con extremos redondeados características del Género Listeria spp.

\section{Identificación confirmativa mediante prue- bas bioquímicas y serológicas}

Para la aplicación de las pruebas bioquímicas, se utilizaron cultivos puros y aislamientos de Listeria spp., cuyas colonias se visualizaron de color azul turquesa. De igual manera se mostraron pruebas positivas para Catalasa y negativas para Oxidasa, junto con la Galería API Listeria, dando positivas sus reacciones. (Ver figuras 1-4).

Figura 1. Se muestra el aislamiento de Listeria spp., comparándose con otros géneros competitivos.

Figura 2: Cultivos puros cuyas colonias se visualizan de azul turquesa.

Figura 3: Pruebas positivas para Catalasa (burbujeo) y negativas para Oxidasa.

Figura 4: Galería API Listeria dando positivas sus reacciones según su color y código. 


\section{Resultados y discusión}

Los resultados obtenidos para Listeria spp. en las muestras ambientales de la empresa, se analizaron mediante el uso de una prueba no paramétrica de distribución de datos. Esta prueba, conocida como X2 (Prueba de Ji-cuadrada) de Pearson, compara la discrepancia y correlación entre dos o más variables.
Se encontraron diferencias altamente significativas de probabilidad al 0.001. Esta cifra es menor a la permitida (probabilidad de error $<0.01$ al 99\% de confiabilidad) entre las zonas de contacto directo versus las de contacto indirecto con la materia prima; y entre el total de las semanas analizadas que constituyeron las réplicas (Ver tabla 1 y figura 5).

Tabla 1. Valores generales por semana para la lectura de Listeria spp.

\begin{tabular}{|c|c|c|}
\hline \multirow{2}{*}{ Semanas } & \multicolumn{2}{|c|}{ Distribución $\mathrm{X}^{2}$ de Pearson ${ }^{2}$} \\
\hline & 24 horas & 48 horas \\
\hline 1 & $875,833.4$ & $1,936,375.0$ \\
\hline 2 & $840,000.2$ & $2,335,000.0$ \\
\hline 3 & $1,879,167.0$ & $3,462,500.0$ \\
\hline 4 & $2,733,333.0$ & $3,329,167.0$ \\
\hline 5 & $31,250.0$ & $120,833.3$ \\
\hline 6 & $483,333.3$ & $1,666,710.0$ \\
\hline \multicolumn{3}{|c|}{ Grados de Libertad $=5 /$ Probabilidad $=0.001$} \\
\hline
\end{tabular}

Nota: Datos tomados a las 24 horas versus 48 horas, según la distribución de medias de la prueba de X2 de Pearson. (a)Unidades expresadas en UFC/ $\mathrm{cm} 2$.

Fuente: Von Chong, M.; Batista, A.; García, R.; Broce, D. 2009. Universidad de Panamá. C.R.U.A. Facultad de Ciencias Naturales, Exactas y Tecnología. Escuela de Biología. Departamento de Microbiología.

Al realizar los análisis estadísticos, se observó que los valores generales por semana que la lectura de Listeria spp. en UFC/cm2 tuvo a las 24 horas fue mayor a la lectura de todas las semanas y/o réplicas de las 48 horas. Esto se hizo más evidente en las semanas uno, dos y seis, cuando las diferencias se duplicaron.
En la gráfica se aprecia que las semanas tres y cuatro tienen el mayor índice de crecimiento. Esto contrasta con la semana cinco en donde el valor resultante es el más bajo, debido a que al momento de realizar el monitoreo rutinario, aún no se había empezado el proceso de producción. 


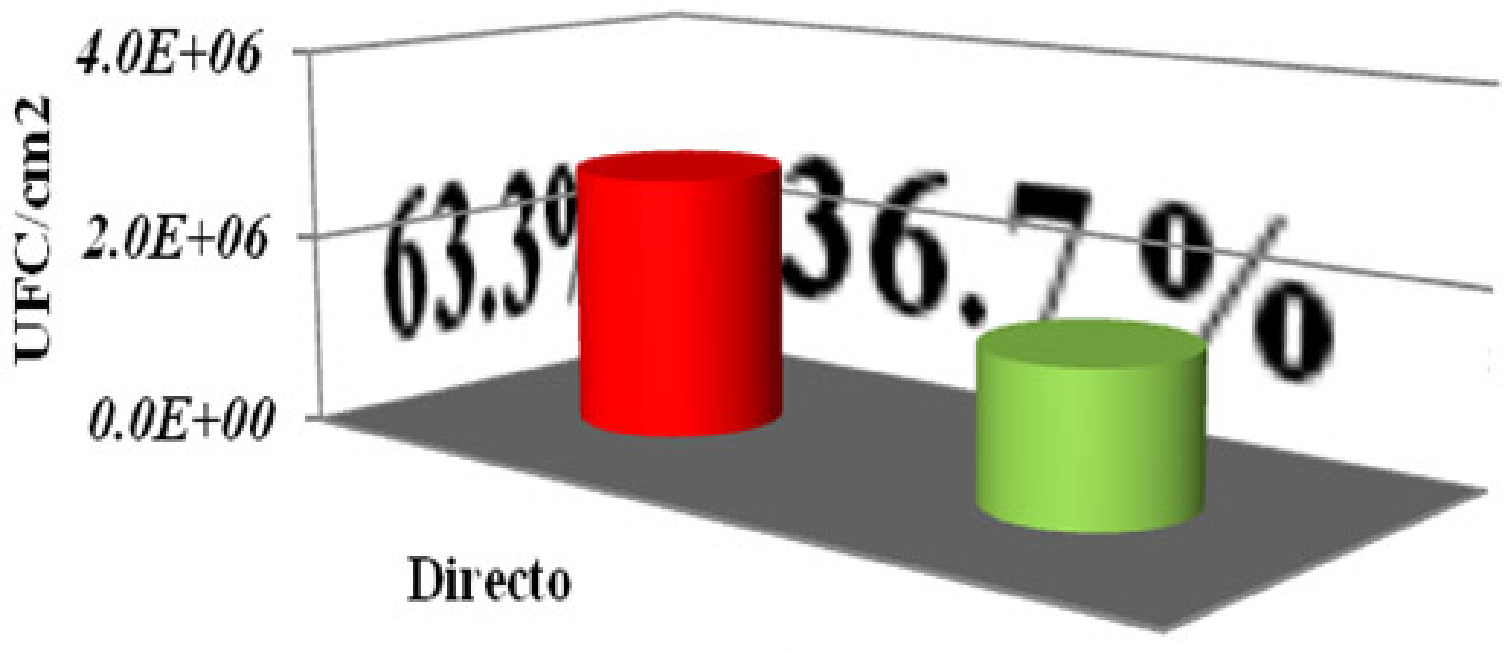

\section{Indirecto}

Figura 5. Gráfico con valores generales por semana para la lectura de Listeria spp. a las 24 horas versus a las 48 horas.

Fuente: Von Chong, M.; Batista, A.; García, R.; Broce, D. 2009. Universidad de Panamá. C.R.U.A. Facultad de Ciencias Naturales, Exactas y Tecnología. Escuela de Biología. Departamento de Microbiología.

Los datos de la tabla 2 confirman que sí existen diferencias altamente significativas en la evaluación de este género bacteriano con un $63.3 \%$ de presencia en las zonas de contacto directo y un $36.7 \%$ las zonas de contacto indirecto

Tabla 2. Valores generales para la lectura de Listeria spp.

\begin{tabular}{|l|c|c|}
\hline \multicolumn{1}{|c|}{ Zonas de Contacto } & ${\text { Distribución X }{ }^{2} \text { de Pearson }}^{\mathrm{b}}$ & Porcentaje $^{\mathrm{c}}$ \\
\hline Directo & $2,729,306.00$ & $63.3 \%$ \\
\hline Indirecto & $1,554,223.00$ & $36.7 \%$ \\
\hline \multicolumn{2}{|c|}{ Grados de Libertad = 1/ Probabilidad = 0.001 } \\
\hline
\end{tabular}

Nota: Datos tomados a las 48 horas entre las zonas de contacto directo versus a las zonas de contacto indirecto, según la distribución de medias de la prueba de X2 de Pearson.

(b) Unidades expresadas en UFC/cm2.

Fuente: Von Chong, M.; Batista, A.; García, R.; Broce, D. 2009. Universidad de Panamá. C.R.U.A. Facultad de Ciencias Naturales, Exactas y Tecnología. Escuela de Biología. Departamento de Microbiología. 


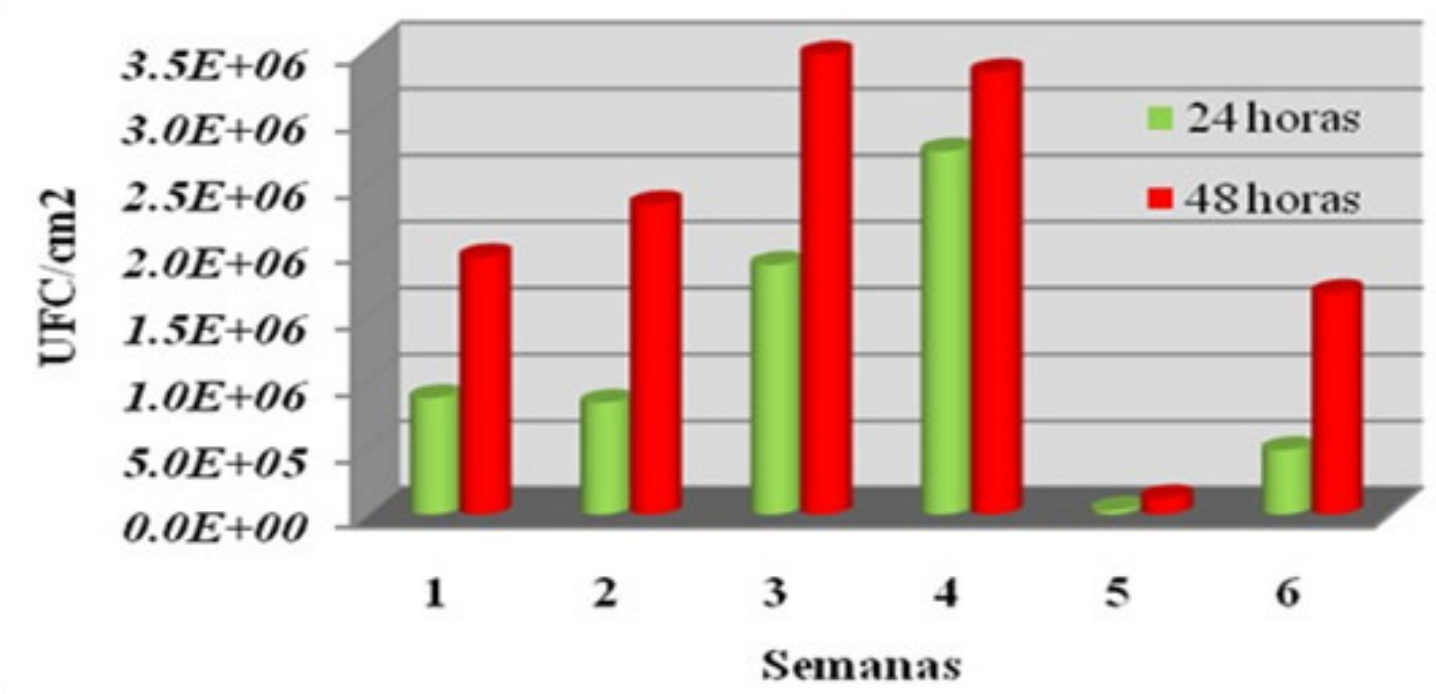

Figura 6. Gráfico comparativo de los valores de Listeria spp. entre las zonas de contacto directo versus a las zonas de contacto indirecto a las 48 horas de lectura.

Fuente: Von Chong, M.; Batista, A.; García, R.; Broce, D. 2009. Universidad de Panamá. C.R.U.A. Facultad de Ciencias Naturales, Exactas y Tecnología. Escuela de Biología. Departamento de Microbiología.

Tabla 3. Relación de los valores generales para la lectura de Listeria spp.

\begin{tabular}{|c|c|}
\hline Unidad Experimental & Distribución $\mathrm{X}^{2}$ de Pearson \\
\hline Máquina de moler (Parte interna) & $2,994,723.00$ \\
\hline Máquina de moler (Parte externa) & $2,463,889.00$ \\
\hline Mesa & $1,536,222.00$ \\
\hline Refrigerador & $1,572,223.00$ \\
\hline \multicolumn{2}{|c|}{ Grados de Libertad $=1 /$ Probabilidad $=0.001$} \\
\hline
\end{tabular}

Nota: Datos tomados a las 48 horas por unidades experimentales entre las zonas de contacto directo versus a las zonas de contacto indirecto, según la distribución de medias de la prueba de X2 de Pearson. (c) Unidades expresadas en UFC/cm2.

Fuente: Von Chong, M.; Batista, A.; García, R.; Broce, D. 2009. Universidad de Panamá. C.R.U.A. Facultad de Ciencias Naturales, Exactas y Tecnología. Escuela de Biología. Departamento de Microbiología.

De acuerdo a la relación existente entre los sitios ambientales monitoreados, se puede apreciar que el punto monitoreado denominado máquina de moler dentro obtuvo un porcentaje de $35 \%$ en la zona de contacto directo, mientras que el punto denominado refrigerador obtuvo el $18.4 \%$ en la zona de contacto indirecto. 


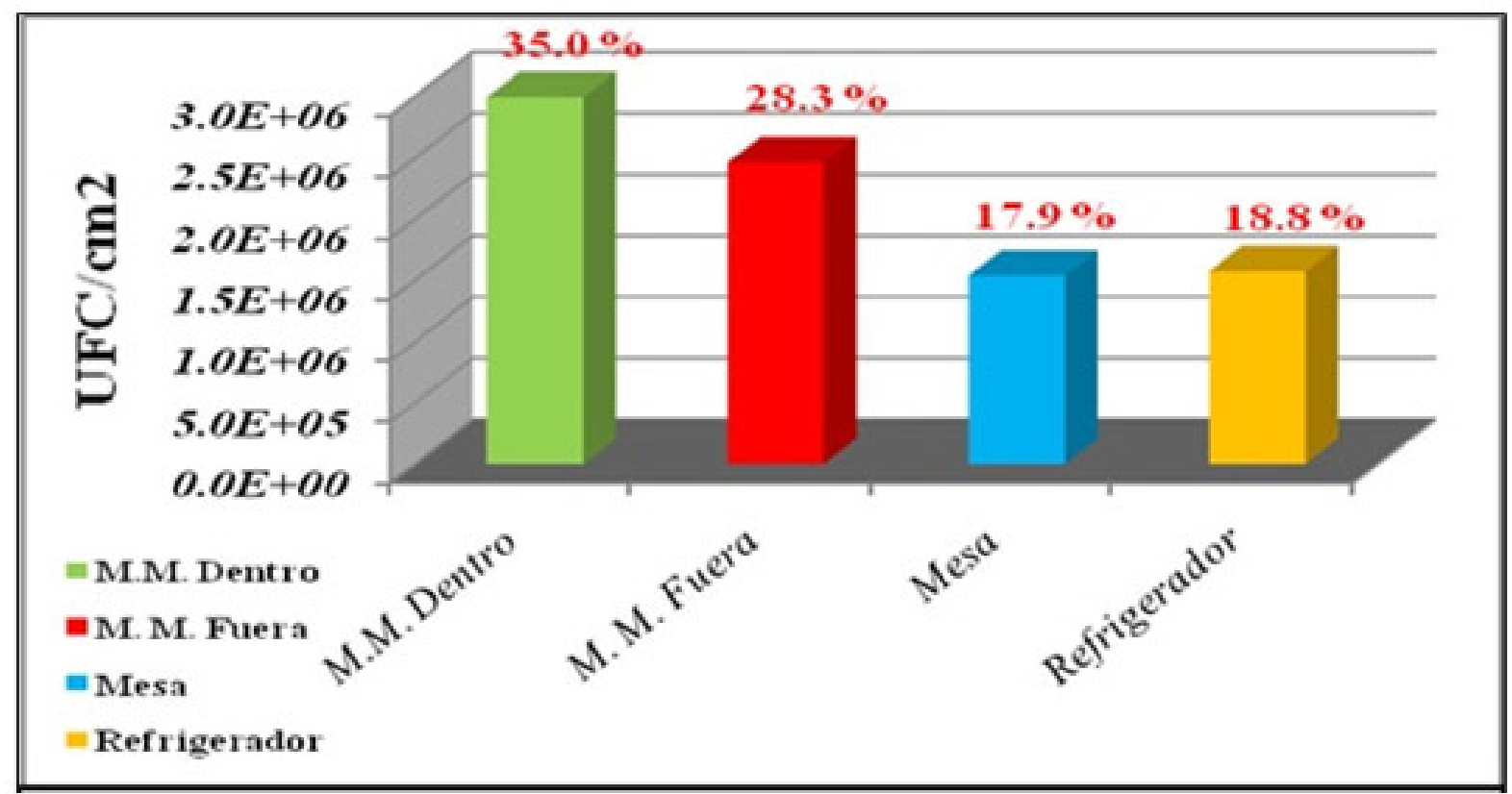

Figura 7. Gráfico de relación de los valores generales para la lectura de Listeria spp. por unidades experimentales entre las zonas de contacto directo versus las zonas de contacto indirecto.

Fuente: Von Chong, M.; Batista, A.; García, R.; Broce, D. 2009. Universidad de Panamá. C.R.U.A. Facultad de Ciencias Naturales, Exactas y Tecnología. Escuela de Biología. Departamento de Microbiología.

Tabla 4. Relación de los valores para la lectura de Listeria spp.

\begin{tabular}{|c|c|c|c|c|}
\hline $\begin{array}{c}\text { Semana } \\
\text { (Réplicas) }\end{array}$ & \multicolumn{4}{|c|}{ Distribución $\mathrm{X}^{2}$ de Pearson en las unidades experimentales ${ }^{\mathrm{d}}$} \\
\hline $\mathbf{X i}^{2}$ & $\begin{array}{c}\text { Máquina de moler } \\
\text { (Parte interna) }\end{array}$ & $\begin{array}{c}\text { Máquina de moler } \\
\text { (Parte externa) }\end{array}$ & Mesa & Refrigerador \\
\hline $\mathbf{1}^{\text {ra }}$ & $10,470,000.0$ & $10,400,000.0$ & $8,803,000.0$ & $16,800,000.0$ \\
\hline $\mathbf{2}^{\mathrm{de}}$ & $10,440,000.0$ & $18,400,000.0$ & $17,600,000.0$ & $9,600,000.0$ \\
\hline $\mathbf{3}^{\text {re }}$ & $33,000,000.0$ & $20,700,000.0$ & $20,700,000.0$ & $8,700,000.0$ \\
\hline $4^{\text {te }}$ & $45,000,000.0$ & $23,300,000.0$ & $2,300,000.0$ & $9,300,000.0$ \\
\hline $\mathbf{5}^{\text {te }}$ & 0 & 0 & $900,000.0$ & $2,000,000.0$ \\
\hline $\mathbf{6}^{\text {te }}$ & $8,900,011.0$ & $15,900,000.0$ & $5,001,002.0$ & $10,200,000.0$ \\
\hline \multicolumn{5}{|c|}{ Grados de Libertad = 15 / Probabilidad = 0.001 } \\
\hline
\end{tabular}

Nota: Datos tomados a las 48 horas por semana versus unidades experimentales, según la distribución de medias de la prueba de X2 de Pearson. (d) Unidades expresadas en UFC/cm2.

Fuente: Von Chong, M.; Batista, A.; García, R.; Broce, D. 2009. Universidad de Panamá. C.R.U.A. Facultad de Ciencias Naturales, Exactas y Tecnología. Escuela de Biología. Departamento de Microbiología. 
Al observar la comparación de los valores para la lectura de Listeria spp. a las 48 horas por semana y unidad experimental, que forma parte de la tabla anterior, se observa una probabilidad del $<0.001$, que indica la dependencia significativa entre los dos factores. Es notorio que los conteos de Listeria spp., en las diferentes unidades experimentales, están influenciadas por las semanas. La unidad con el mayor conteo fue la máquina de moler dentro (contacto directo), con un promedio de $3.3 \mathrm{x}$
$107 \mathrm{UFC} / \mathrm{cm} 2$ y 4.5 x $107 \mathrm{UFC} / \mathrm{cm} 2$. Esto sucedió en la tercera y cuarta semana, respectivamente. Sin embargo, en la primera semana el refrigerador (contacto indirecto) obtuvo un promedio de 1.047 x $107 \mathrm{UFC/cm2}$. Quedando la quinta semana con menor promedio de Listeria spp. En general, la máquina de moler dentro y la máquina de moler fuera obtuvieron los menores promedios durante esas semanas.

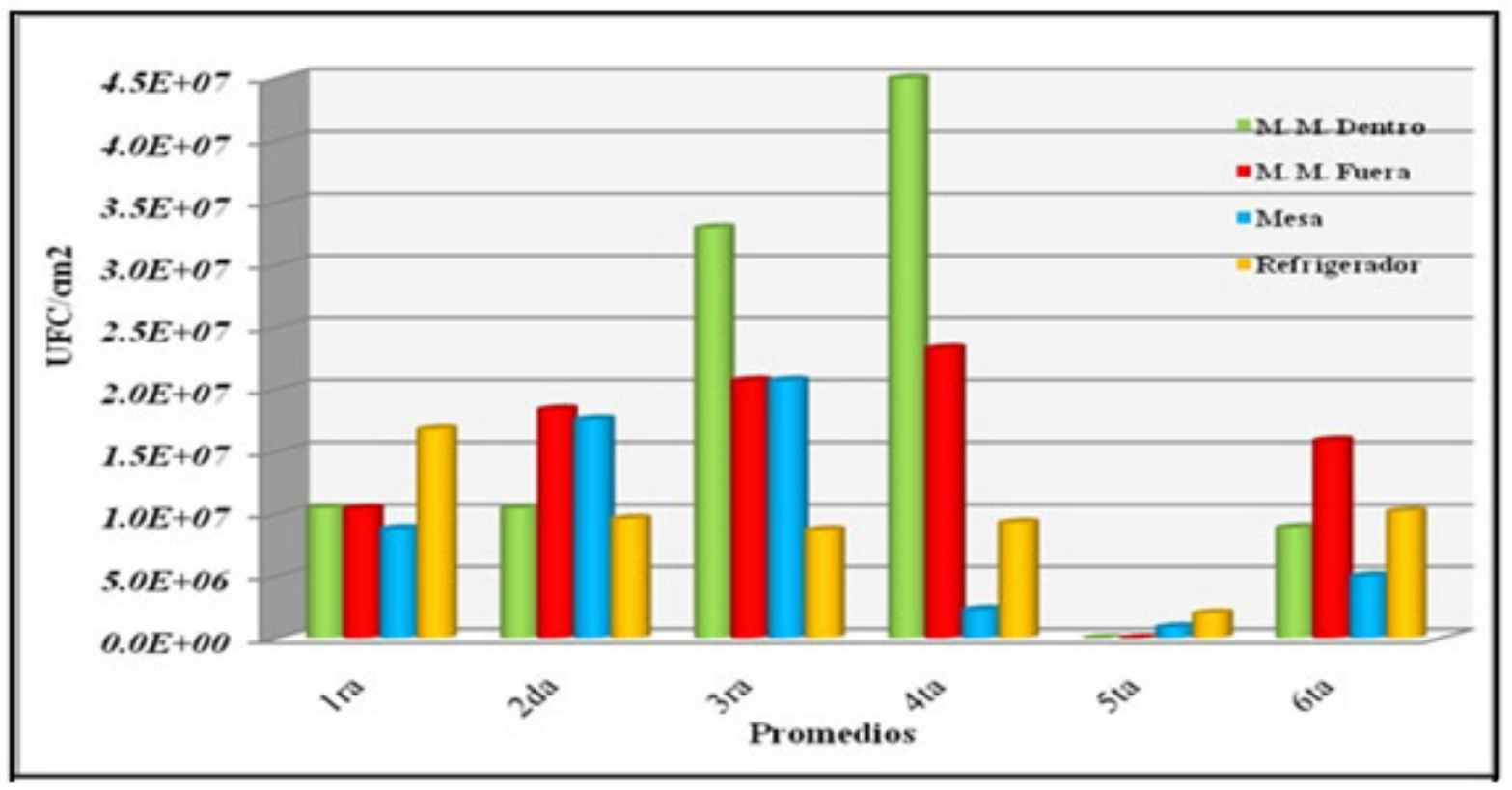

Figura 8. Relación de los valores para la lectura de Listeria spp. a las 48 horas por semana versus unidades experimentales.

Fuente: Von Chong, M.; Batista, A.; García, R.; Broce, D. 2009. Universidad de Panamá. C.R.U.A. Facultad de Ciencias Naturales, Exactas y Tecnología. Escuela de Biología. Departamento de Microbiología. 


\begin{tabular}{|c|c|c|c|c|c|}
\hline $\begin{array}{c}\text { Tinción } \\
\text { de } \\
\text { Gram }\end{array}$ & Semanas & Catalasa & Oxidasa & $\begin{array}{c}\text { API } \\
\text { Listeria } \\
\text { (Código) }\end{array}$ & $\begin{array}{l}\text { Especie } \\
\text { resultante }\end{array}$ \\
\hline \multirow{6}{*}{$\begin{array}{c}\text { Formas } \\
\text { coco-bacilares } \\
\text { de coloración } \\
\text { purpura o } \\
\text { violeta }\end{array}$} & Primera & + & - & 6200 & L. seeligeri \\
\hline & Segunda & + & - & 2021 & L. grayi \\
\hline & Tercera & + & - & 6221 & L. welshimeri \\
\hline & Cuarta & + & - & 6020 & L. grayi \\
\hline & Quinta & + & - & 6200 & L. seeligeri \\
\hline & Sexta & + & - & 6221 & L. welshimeri \\
\hline
\end{tabular}

Figura 9. Resultados obtenidos en la identificación de las especies de Listeria spp. mediante pruebas bioquímicas aplicadas a cultivos puros de cepas y colonias frescas.

Fuente: Von Chong, M.; Batista, A.; García, R.; Broce, D. 2009. Universidad de Panamá. C.R.U.A. Facultad de Ciencias Naturales, Exactas y Tecnología. Escuela de Biología. Departamento de Microbiología.

\section{L. seeligeri $\square$ L. grayi $\square$ L. welshimeri}

\section{Series 1}

Series 2

\section{L.welshimeri,}

$33.33 \%$ $33 \%$

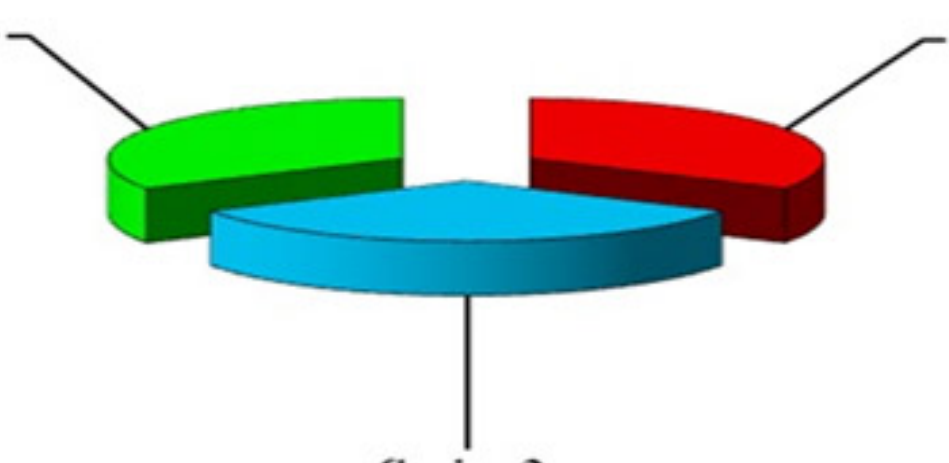

L. seeligeri

Series 3

$33.33 \%$, $34 \%$

\section{L. grayi \\ $33.33 \%$ $33 \%$}

Figura 9. Porcentajes de presencia de Listeria spp. al realizar pruebas de confirmación bioquímica por medio de la prueba API para Listeria spp.

Fuente: Von Chong, M.; Batista, A.; García, R.; Broce, D. 2009. Universidad de Panamá. C.R.U.A. Facultad de Ciencias Naturales, Exactas y Tecnología. Escuela de Biología. Departamento de Microbiología. 


\section{Conclusiones}

El estudio permitió establecer la existencia de diferencias altamente significativas en la evaluación de Listeria spp., obtenidas en las superficies ambientales de monitoreo en sitios de contacto directo versus sitios de contacto indirecto con la materia prima, dentro de una empresa de producción artesanal de quesos frescos. Dichas diferencias se encontraron al realizar los análisis estadísticos, mediante la prueba de distribución de medias de X2 de Pearson, la cual midió la discrepancia entre estas dos variables.

Hay que destacar que los monitoreos se realizaron en el mismo tiempo en que se llevó a cabo el proceso de fabricación del queso fresco blanco. Tras la realización de las pruebas, se demostró que el origen de la contaminación de Listeria spp. se debe en gran medida a deficientes condiciones higiénicas de manufactura, como lo establece Cutter y col. (2006). Estos autores afirman que la presencia de este microorganismo en las plantas de producción de alimentos es propicia para que ocurra contaminación cruzada, ya que el microorganismo es transferido de una superficie a otra. Ello contamina los alimentos inocuos y los equipos limpios, debido a la existencia de las biopelículas. Igualmente este indicador puede sobrevivir en el ambiente, debido a la entrada y salida de personal, de la materia prima y del producto terminado, haciéndose muy difícil su control.
Al comparar los valores generales para la lectura de Listeria spp. a las 48 horas entre las superficies ambientales de contacto directo e indirecto con la materia prima, se comprobó lo expuesto por Díaz y otros (2003), quienes afirman que el crecimiento de Listeria spp. está influenciado por la temperatura, la actividad de agua y la accesibilidad a los nutrientes, ya que estas bacterias son relativamente exigentes. Otro factor de impacto fueron las condiciones para el crecimiento de la bacteria en los ambientes monitoreados.

Existen diferencias altamente significativas entre las zonas de contacto directo con la materia prima y las zonas de contacto indirecto, en base al recuento de Listeria spp. obtenidos en la investigación. En la zonas de contacto directo, el crecimiento del patógeno fue de $63.3 \%$; mientras que en las otras zonas fue de $36.7 \%$.

La unidad experimental con mayor recuento de Listeria spp. resultó ser la máquina de moler dentro, con un porcentaje de 35\% en la zona de contacto directo. Por su parte, la unidad experimental con mayor recuento de Listeria spp., en la zona de contacto indirecto, fue el refrigerador con un porcentaje de $18.4 \%$.

No obstante, un resultado importante fueron los datos de la quinta semana, en donde el crecimiento de Listeria spp., para las unidades experimentales de contacto directo e indirecto, disminuyeron debido a que el muestreo se realizó antes del procesamiento. Sin embargo, 
esta es una características lógica de la especie patógena L. monocytogenes, la cual vive y crece a temperaturas de refrigeración (menos de $\left.4^{\circ} \mathrm{C}\right)$. Durante la semana antes mencionada, el crecimiento fue mayor en el refrigerador.

A pesar de que el patógeno crece lentamente a esta temperatura, el largo tiempo de refrigeración de muchos alimentos listos para consumir, podría brindarle la oportunidad de crecer a niveles peligrosamente altos, según lo afirman Cutter y otros (2006). También es posible que, cuando en los alimentos existe una carga elevada de microorganismos de alteración, estos compitan por el espacio y los nutrientes. Igualmente influyen las diferentes tasas de crecimiento de las cepas de Listeria spp., las interacciones con el alimento en la fase de enriquecimiento, y la producción de bacteriocinas en las distintas semanas de monitoreo ambiental realizadas en la empresa.

Por otro lado, existe una notable dependencia entre las semanas monitoreadas y el recuento de Listeria spp. en muestras ambientales, dentro de la empresa de producción artesanal de quesos frescos.

Todo esto constituye una serie de factores que afectan la ecología microbiana de las distintas especies de Listeria spp., presentes en la matriz alimentaria, favoreciendo así la recuperación de unas especies en detrimento de otras, según Rodríguez, (2001) y Pelisser y otros (2001). De esta forma se detectaron algunas especies en pruebas bioquímicas realizadas, pero no así el patógeno denominado Listeria monocytogenes, la cual no pudo ser aislada durante esta investigación. Las especies de Listeria spp. que se aislaron e identificaron en este estudio, mediante el empleo de pruebas bioquímicas, fueron las siguientes: L. grayi, L. seeligeri, L. welshimeri.

Adicionalmente, estudios comprobados afirman que tanto L. innocua como las demás especies identificadas en esta investigación - que forman dicho género - comparten el nicho ecológico con L. monocytogenes; teniendo cierta ventaja competitiva frente a este patógeno, por tener una velocidad específica de crecimiento superior (Gallegos y col. 2007). Probablemente, por esta razón, no se pudo encontrar este patógeno emergente oportunista. 


\section{Referencias}

Alcázar, C. y otros (2006). Detección de Salmonella spp. y Listeria monocytogenes en quesos frescos y semimaduros que se expenden en vía pública en la ciudad de México. Revista Vet. México, 37(4): 417-429. Recuperado de: http://www.medigraphic.com/espanol/e-htms/e-vetmex/em-vm.htm.

Batista A.; Garcia R. (2009). Evaluación de Listeria spp. en muestras ambientales en una Empresa de Producción Artesanal de Quesos Frescos en La Provincia de Los Santos. Universidad de Panamá. Centro Regional Universitario de Azuero. Facultad de Ciencias Naturales y Exactas. Tesis de Licenciatura.

Biomériux (2007). Sistema de Identificación de Listeria. API Listeria. Francia. Biomeriux Internacional.

Cabrera, C.; Hurtado, A.; Perez, M. (2004). Búsqueda de Listeria spp. en quesos frescos procesados en Rancherias del Municipio de Tecate. Universidad Autónoma de Baja California. Facultad de Ciencias Químicas e Ingeniería. Recuperado de: www.uaemex.mx/Red_Ambientales/docs/ congresos/Ciudad\%200bregon/TOXICOLOGIA_Y_SALUD/TXA009.doc

Centers For Disease Control And Prevention. Cdc. (2008). Listeriosis. United States Department of Health and human Services. Recuperado de: http://www.cdc.gov/nczved/dfbmd/ disease_listing/listeriosis_gi.html.

Comisión Del Códex Alimentarius (2008). Anteproyecto de Directrices para el Control de Listeria Monocytogenes en los Alimentos. Comité del Códex sobre Higiene de los Alimentos. Programa conjunto FAO/OMS sobre Normas Alimentarias. Cuadragésima (40) Reunión. Recuperado de: www.codexalimentarius.net/download/report/714/fh40_01s.pdf

Comisión Mixta Fao/Oms Del Códex Alimentarius (Cac); Comité Del Códex Sobre Higiene De Los Alimentos (Ccfh) (2004). Evaluación de riesgos de Listeria monocytogenes en alimentos listos para el consumo; resumen interpretativo. Recuperado de: ftp://ftp.fao.org/docrep/ fao/008/y5393s/y5393s00.pdf

Cutter, C.; Mcelroy, C.; Penn, S. (2006). El control de Listeria monocytogenes en Establecimientos de Ven al Consumidor o al Detalle. College of Agricultural Sciences Agricultural Research and Cooperative Extension. Penn-State University, en cooperación con el Servicio de Inspección e Inocuidad Alimentaria del USDA y la Asociación de Oficiales de Alimentos y Medicinas. Estados Unidos. Recuperado de: www.cas.psu.edu 
Davis, B. y otros (1973). Microbiology, Chapter 41. Other Pathogenic Bacteria. Second edition. Haper \& Row, Publishers Inc. Hagerstown, Maryland. Pág. 946-948.

Díaz G.; Ferrán J. (2003). Fundamentos y técnicas de análisis microbiológicos. Bacilos Gram Positivos; Listeria Monocytogenes. Laboratorio de Diagnóstico Clínico. Recuperado de: http:// chopo.pntic.mec.es/ gdiaz3/apuntes/UT126.pdf

Figueroa, B.; Caballero, A.; Villalobos, L. (2005). Crecimiento de Listeria monocytogenes en atún ahumado empacado al vacío. Rev. Zootecnia Trop. online. abr. 2005, vol.23, no.2 págs. 171-181. Recuperado de: http://www.scielo.org.ve/scielo.php?script=sci_arttext\&pid=S0798$72692005000200006 \& \operatorname{lng}=\mathrm{es} \& \mathrm{nrm}=\mathrm{iso}>$.

Food And Drugs Administration. FDA. (US FDA/CFSAN) (2005). Seguridad alimentaria para futuras mamás; Prevención de la listeriosis. Recuperado de: http://www.cfsan.fda. gov/ pregnant/spwhilli.html.

Food Safety And Inspection Service (FSIS) (2004). Assessing the Effectiveness of the Listeria monocytogenes Interim Final Rule. Washington D. C. Recuperado de: http://www.fsis.usda. gov/Oppde/rdad/frpubs/97-013F/LM_Assessment_Report_2004.pdf

Hydra-Sponge With Buffered Peptone (3M) (2008). Water Broth HS10BPW. Hydrated sponge 10mL Buffered Peptone Water Broth, 100/case. Recuperado de: http://solutions.3m.com/wps/ portal/3M/en_US/Microbiology/FoodSafety/product-information/productcatalog/?PC_7_ RJH9U523003DC023S7P92O3O87_nid=JB6N15Z9QBbeZD53Z9PHFHgl

International Commission On Microbiological Specifications For Foods (ICMSF) (2002). Microrganismos de los Alimentos. Análisis Microbiológico en la Gestión de la Seguridad Alimentaria. Editorial Acribia S. A., Zaragoza, España. Pág. 209-316.

Kenneth, R; George. R. (2005). Sherris. Microbiología Médica. Una introducción a las enfermedades infecciosas. Capitulo 18. McGraw Hill. México. Pág. 328-331.

Koneman, E.W. y otros (2005). Koneman's color atlas and textbook of diagnostic microbiology. Chapter 5, Edition 6. Lippincott Williams \& Wilkins, United States. 1565 páginas.

Lennette, E. y otros (1985). Manual of Clinical Microbiology. Fourth edition. American Society for Microbiology, Washington, D.C. Pág. 205-208.

Madigan, M. T.; Martinko, J. M.; y Parker, J. (2004). Brock. Biología de los Microorganismos, Capítulo 29, 10a edición. Pearson Educacion, S.A., Madrid. Pág. 953-954. 
Márquez, J. G.; García, C. E. (2007). Microflora Patógena Del Queso Blanco " Telita" Elaborado en Cuatro Estados de Venezuela. An Venez Nutr. online., vol.20, no.1 p.17-21. Recuperado de: http://www.scielo.org.ve/scielo.php?script=sci_arttext\&pid=S0798-07522007000100004\&lng=es \&nrm=iso $>$. ISSN 0798-0752.

Martino, T. y otros (2005). Determinación de Listeria spp. en quesos y embutidos comercializados en Cuba. Rev. Cubana Salud Pública 2005; 31 (3): 217-22. Recuperado de: http://www.scielosp. org/scielo.php?pid=S0864-34662007000300002\&script=sci_arttext.

Moreno, R. I. y otros (2005). Caracterización de cepas de Listeria monocytogenes aisladas durante la cadena de producción y comercialización de queso fresco. Recuperado de: http://www.ciad. $\mathrm{mx} /$ boletin/novdic05/monocytogens.pdf

Ottaviani y Agosti (2008). Agar Listeria Monocytogenes Selectivo acc. Guía de uso. Biokar Diagnostics.

Pelisser, M. y otros (2001). Detection of Listeria spp. In refrigerated chicken carcasses uning clearview and a modified conventional culture method. Rev. Brazilian Journal of Microbiology. Vol: 32:113-116. Recuperado de: http://www.scielo.br/pdf/bjm/v32n2/a08v32n2.pdf

Rodríguez, J. (2001). Listeria monocytogenes, el patógeno alimentario del futuro inmediato. Revista Consumer Eroski. Recuperado de: http://www.consumer.es/seguridad-alimentaria/ciencia-y-tecnologia/2001/08/09/347.php

Universidad Nacional De Panamá (1998). Guía metodológica trabajo de graduación. Facultad de Ciencias Naturales Exactas y Tecnología. Escuela de Biología.

U.S Food And Drug Administration. FDA. (2003). Detección y enumeración de Listeria Monocytogenes en alimentos. Bacteriological Analytical Manual online. Enero de $2003 . \quad$ Recuperado de: http://www.oie.int/esp/normes/mmanual/pdf_es/2.10.14_Listeria_monocytogene

US Department Health and Human Services /FDA/CFSAN and USDA/FSIS (2008). Draft assessment of the relative risk to public health from foodborne Listeria monocytogenes among selected categories of ready-to-eat foods. Recuperado de: http://www.foodsafety.gov/ dms/lmrisk.html.

Vera H.; Ferro, C. Triana, L. (2001). Prevalencia de Listeria monocytogenes en derivados cárnicos cocidos para consumo directo. Analizados en el Laboratorio de Salud Pública, de la Secretaria Distrital de Salud; Colombia. Recuperado de: http://chopo.pntic.mec.es/ gdiaz3/apuntes/UT126.pdf 